\title{
Issues in Cost Containment
}

\section{Impact of a Cost Containment Program on the Use of Volatile Anesthetics and Neuromuscular Blocking Drugs}

\author{
James F. Szocik, MD,* David W. Learned, MD†
}

Department of Anesthesiology, University of Michigan, Ann Arbor, MI.

Study Objective: To determine the impact of a cost containment program on the use of volatile anesthetics and neuromuscular blocking drugs.

Design: Historical, controlled, retrospective analysis.

Setting: Main operating rooms of an adult general hospital at a university medical center.

Patients: All patients undergoing anesthesia between July 1991 and November 1993. Measurements and Main Results: Cost per case was determined by dividing the monthly expenditure for each class of drug by the caseload for that month. Cost per case of volatile anesthetic drugs decreased from $\$ 19.20 \pm 1.16$ to $\$ 15.16 \pm 0.39(\mathrm{p}=$ 0.0034 by unpaired t-test). For neuromuscular blocking drugs, cost per case decreased from $\$ 19.67 \pm 1.35$ to $\$ 12.23 \pm 0.66(\mathrm{p}=0.003)$.

Conclusions: Concerted educational efforts can decrease the per case expenditures for both volatile anesthetic drugs and neuromuscular blocking drugs.

Keywords: Anesthetics, volatile; cost control; nondepolarizing neuromuscular blocking drugs.

*Lecturer in Anesthesia

†Assistant Professor of Anesthesia

Address reprint requests to $\mathrm{Dr}$. Szocik at the Department of Anesthesiology, University of Michigan Medical Center, 1500 E. Medical Center Drive, UH-1G323, Box 0048, Ann Arbor, MI 48109-0048, USA.

Received for publication March 7, 1994; revised manuscript accepted for publication May 24, 1994.

(C) 1994 Butterworth-Heinemann

J. Clin. Anesth. 6:378-382, 1994.

\section{Introduction}

Expenditures by anesthesia providers may represent $3 \%$ to $5 \%$ of the total U.S. health care costs of $\$ 800$ billion. $^{1}$ These costs include preoperative laboratory evaluations, cost of equipment, salaries of anesthesia providers and support personnel, and cost of pharmacologic drugs. At the University of Michigan Medical Center, $54 \%$ of the Department of Anesthesiology's budget went for salaries (Figure 1), which concurs with other reports in the literature. ${ }^{2}$ The other major expenditure was for pharmacy charges. At our institution, the total pharmacy charges per anesthetic were approximately $\$ 75$. Half of these charges were for two classes of drugs: volatile anesthetic drugs and neuromuscular blocking drugs (Figure 2). In the interest of curbing continuing increases in expenses, a quality improvement team was formed to study the use of volatile anesthetics in the operating rooms of the Adult General Hospital.

Quality improvement, or total quality management (TQM), is a concept taken from the work of W. Edwards Deming. ${ }^{3}$ The principles of TQM are now being applied to the practice of medicine. As implemented at the University of Michigan, the team process involved seven steps designed to determine the root cause of a problem and to formulate an appropriate response. The 


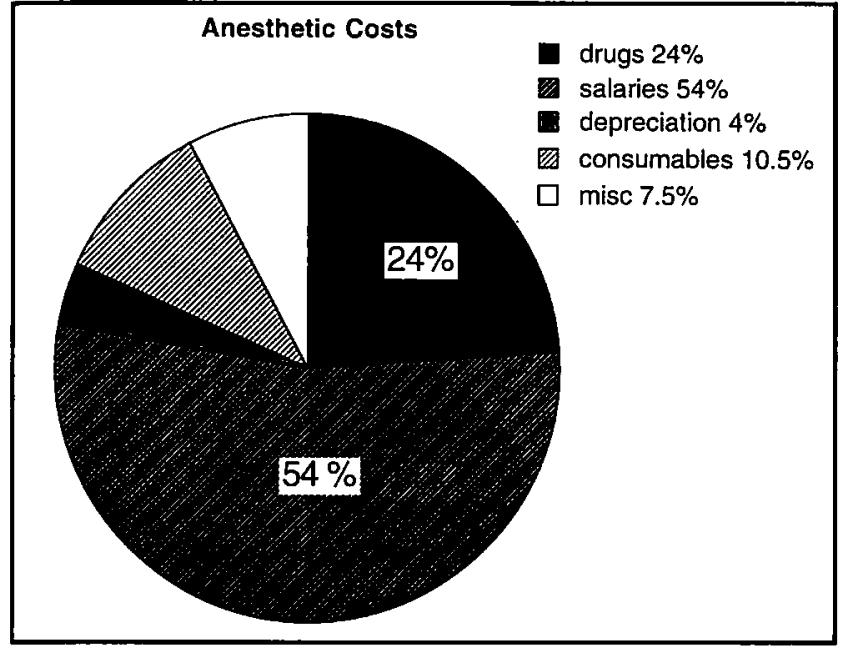

Figure 1. Anesthetic department budget by category. Data from fiscal year 1992-93. Total budget was $\$ 6,376,617$.

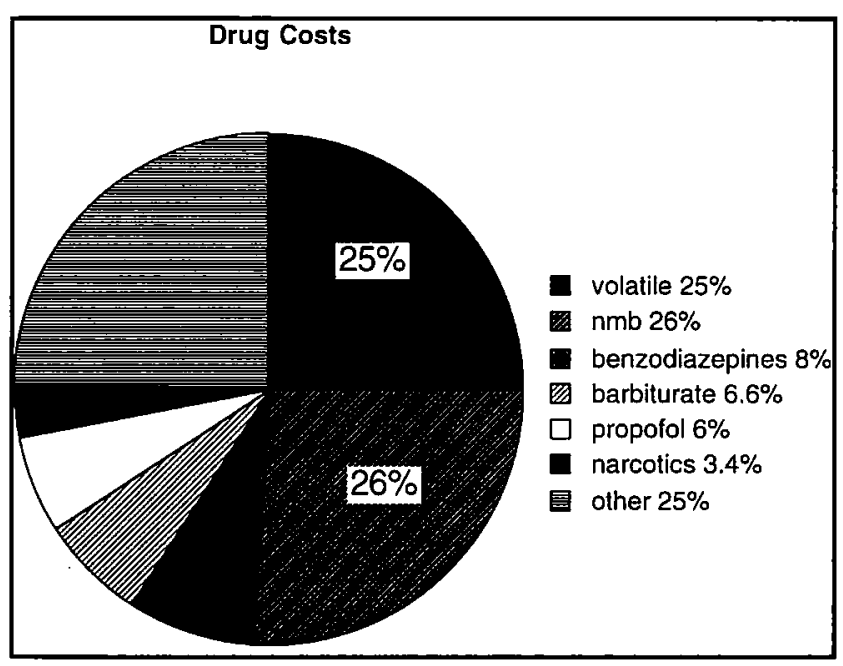

Figure 2. Pharmacy charges by category. Data from fiscal year 1992-93. Total charges were $\$ 1,216,446$. $\mathrm{nmb}=$ neuromuscular blocking drugs.

sequence of efforts within the seven steps was as follows: (1) identification of a theme that would describe our problem and opportunity for change; (2) determination of an indicator that would enable our tracking of progress; (3) characterization of the current situation, written as a clear, concise problem statement; (4) cause-andeffect analysis, leading to the discovery of root causes of the problem; (5) evaluation of possible countermeasures, systematically looking for the measures that would yield the greatest effect for the effort; (6) implementation of countermeasures to determine effectiveness; (7) establishment of practice guidelines and continued monitoring of countermeasures.

Applying steps 1 through 4 resulted in the following hypothesis: application of educational countermeasures (publication of drug costs to the faculty and at the site of use, instruction in low-flow anesthetic technique, and teaching rational selection of neuromuscular blocking drugs) will decrease the per case cost of the following drugs: volatile anesthetics, neuromuscular blocking drugs, and nitrous oxide $\left(\mathrm{N}_{2} \mathrm{O}\right)$. This study reports the results of applying these principles of cost containment to anesthetic drugs.

\section{Materials and Methods}

Educational intervention consisted of multiple steps, including (1) listing all drug and supply costs on a centralized database accessible to all faculty members via a computer server and at the site of use (anesthesia carts); (2) a formal lecture on the conduct of low-flow anesthesia, delivered in October 1992, which served as the categorical division between "before" and "after"; (3) equipping each operating location with a drug analyzer to facilitate the teaching of low-flow and closed-circuit anesthesia; (4) discussion of cost at each morning's preanesthetic conference; (5) discussion of cost containment measures at faculty meetings; and (6) intensive oneon-one teaching of low-flow anesthetic techniques and principles of uptake and distribution. Low-flow anesthesia was defined as flows at or below $1.5 \mathrm{~L} / \mathrm{min}$ after 30 minutes of anesthesia.

Concurrent with cost containment efforts aimed at decreasing volatile anesthetic use via low-flow delivery techniques, efforts were made to decrease the per case cost of neuromuscular blocking drugs. Initial surveys indicated that average vecuronium use was as high as one vial (10 mg) per case. To decrease waste of neuromuscular blocking drugs, residents were discouraged from routine preparation of neuromuscular blocking drugs and encouraged to fractionate the dose into several syringes to enable use among several patients without risk of contamination. Additionally, given that the average case duration at the Adult General Hospital was 2.9 hours and the duration of vecuronium is well under 1 hour, vecuronium should not be the drug of choice for muscle relaxation at the University of Michigan. Pancuronium has a duration of action compatible with a case of 3 hours' duration and a cost per case one-tenth that of vecuronium. Therefore, suggestions were made that, unless the patient had a contraindication to pancuronium, it should be the drug of choice for neuromuscular relaxation. All final decisions were made by the attending staff anesthesiologist. The form of anesthesia and the drugs to be used were always at the discretion of the staff anesthesiologist.

Data were collected by a retrospective analysis of ordering for the following drugs: isoflurane, enflurane, pancuronium, vecuronium, atracurium, and $\mathrm{N}_{2} \mathrm{O}$. Case data were obtained from the departmental billing office. For volatile drugs and neuromuscular blocking drugs, each month's ordering costs were totaled, then the total was divided by the cases in that month. For $\mathrm{N}_{2} \mathrm{O}$, which was delivered in bulk on a quarterly basis, each delivery was divided by the preceding 3 month's caseload. Total 
cost of commodities was divided by the caseload to determine the total cost per case of commodities on a yearly basis for 1989 to 1993 . Quality assurance (QA) data were obtained from April 1991 to November 1993 to track the occurrence of reintubation as an indicator of inadequate reversal of neuromuscular blocking drugs.

Costs were standardized at a per unit rate for the duration of the study as follows: pancuronium, $\$ 1.63 / 10$ $\mathrm{mg}$; vecuronium, $\$ 17.70 / 10 \mathrm{mg}$; atracurium, $\$ 37.80 / 100$ $\mathrm{mg}$; isoflurane, $\$ 88.97 / 100 \mathrm{ml}$; enflurane, $\$ 150.13 / 250$ $\mathrm{ml} ; \mathrm{N}_{2} \mathrm{O}, \$ 0.49 /$ cubic foot; propofol, $\$ 9.51 / 200 \mathrm{mg}$ or $\$ 24.78 / 500 \mathrm{mg}$. Standardization of cost was done to study changes in utilization rather than cost per se, as cost may have varied with supplier or over the time course of the study.

Statistical analysis was by unpaired t-test for groups either before October 1992 or after October 1992. Significance was set at $p<0.05$. Data are reported as means \pm SEM. The $n$ indicates the number of months studied for volatile drugs, propofol, and neuromuscular blocking drugs, or, in the case of $\mathrm{N}_{2} \mathrm{O}$, the number of deliveries.

\section{Results}

To determine the effect of educational interventions on volatile anesthetic use, a baseline was established by retrospective analysis of the 15 months prior to October 1992. During this time, the per case cost of volatile anesthetics at the Main Hospital was $\$ 19.20 \pm 1.16(\mathrm{n}=15)$. In the 14 months following the educational interventions, volatile anesthetic per case cost decreased significantly to $\$ 15.16 \pm 0.39(\mathrm{n}=14)(p=0.0034$; Figure 3). This represents a decrease of $\$ 4.04$, or $21 \%$, per case. Multiplied by a caseload of approximately 16,000 cases per year, this results in a savings of more than $\$ 60,000$ per year.

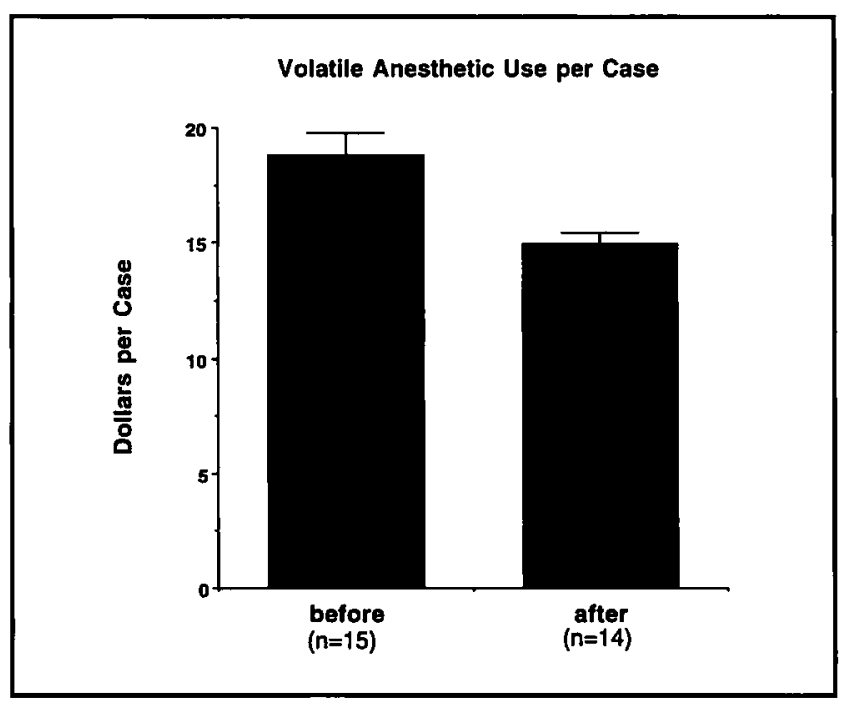

Figure 3. Cost of volatile anesthetics before and after intervention. $* p<0.05$.

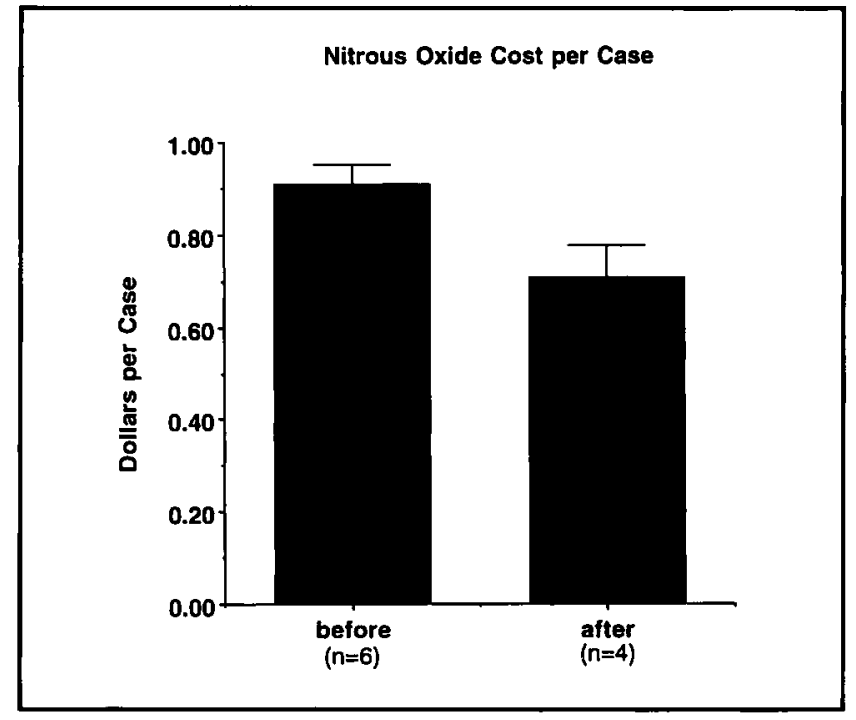

Figure 4. Cost of nitrous oxide before and after intervention. $* p<0.05$.

As a check against other drugs being substituted for volatile anesthetics, propofol use also was tracked and showed no significant change over the study period $(p=0.1926)$. As a further confirmation of these reductions in volatile anesthetic use being attributable to lowflow anesthetic techniques, the per case utilization of $\mathrm{N}_{2} \mathrm{O}$ was investigated. This also showed a reduction in cost per case, from $\$ 0.907 \pm 0.044(n=6)$ to $\$ 0.707$ $\pm 0.069(n=4)$, or $22 \%(p=0.325$; Figure 4$)$.

Efforts to decrease the cost per case of neuromuscular blocking drugs also were successful. The primary effort was toward the substitution of pancuronium for vecuronium when there was no contraindication and anesthesia time was greater than 90 minutes. Following these measures, a marked reduction in total cost for neuromuscular blocking drugs was noted after October 1992. Cost per case decreased from $\$ 19.67 \pm 1.35(\mathrm{n}=3)$ to $12.23 \pm$ $0.66(n=14)$, a reduction of nearly $38 \%(p=0.003$; Figure 5). Multiplied by the caseload, this figure represents a savings of nearly $\$ 120,000$ in an annual budget.

As a decrease in cost per case of volatile anesthetics, $\mathrm{N}_{2} \mathrm{O}$, and neuromuscular blocking drugs may be due to a decrease in the percentage of cases done as general anesthetics, we calculated the percentage of cases done as general anesthetics in the before and after periods. These data show that the percentage of general anesthetic cases increased from $71.3 \% \pm 0.5 \%(n=15)$ to $75.2 \% \pm 0.6 \%(\mathrm{n}=14)(p<0.0001)$.

QA data regarding possible complications of these measures, specifically reintubation, were inconclusive. In the 14 months' worth of available data preceding the implementation of cost containment measures, there were 13 reintubations in the Adult General Hospital, resulting in a frequency of $0.066 \%$ ( 13 reintubations out of 19,739 cases). Pancuronium was involved in 3 reintubations, vecuronium in 3, and succinylcholine in 2. Data 
Cost of Neuromuscular Blocking Drugs per Case

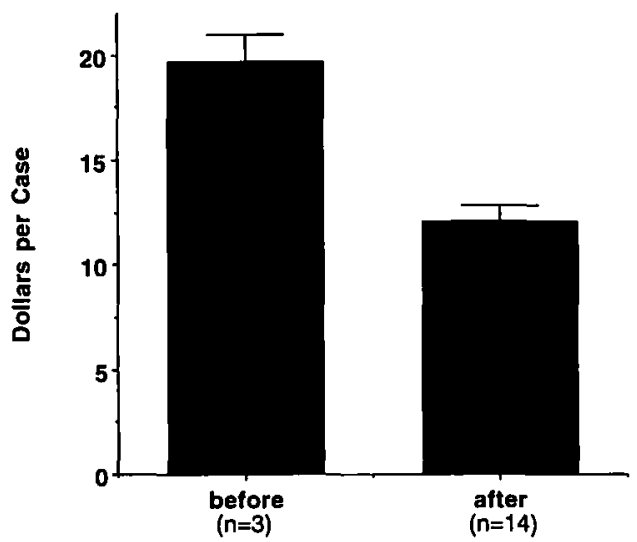

Figure 5. Cost of neuromuscular blocking drugs before and after intervention. ${ }^{*} p<0.05$.

to determine which neuromuscular blocking drug was used were lacking in 5 charts. For the 11 months' worth of available data after implementation, there were 10 reintubations out of 14,927 cases, resulting in a frequency of $0.067 \%$. Of these 10 cases, 2 involved pancuronium, 3 vecuronium, and 1 atracurium; the neuromuscular blocking drugs in the other 4 cases were undetermined. Theoretically, use of pancuronium could result in an increase in the need for postoperative ventilatory support.

Total cost of commodities per case ranged from a high of $\$ 116.45$ in 1991 to a low of $\$ 104.83$ in 1993 .

\section{Discussion}

Cost containment measures initiated as part of a quality improvement program have decreased the cost per case of a number of anesthetic drugs at the University of Michigan Medical Center. Previous reports have been made on the theoretical analysis of anesthetic costs ${ }^{1}$ and the potential benefits (cost-effectiveness) of several drugs. ${ }^{4,5}$ The use of older, less expensive neuromuscular blocking drugs and low-flow anesthesia has been thought to decrease costs for a number of years. ${ }^{6,7}$ To our knowledge, our study is the first report on the actual clinical efficacy of such measures.

Despite the success at decreasing expenditures for pharmaceutical drugs, there are limitations to these approaches. Without adequate instruction in low-flow anesthesia, providers may risk inadequate anesthesia, especially at induction, or excessive anesthesia, especially during a lengthy case. For these reasons, implementation of low-flow anesthesia as a routine practice was delayed until the introduction of drug monitors in each room. The one-time cost of the new monitors was weighed against the potential continuing savings of low-flow anes- thesia, although the new monitors were scheduled to be purchased in any case.

Additionally, as flows are lowered, mechanical limitations become apparent. A $100 \mathrm{ml} / \mathrm{min}$ leak that is not noticeable at $3 \mathrm{~L} / \mathrm{min}$ flows becomes a $50 \%$ loss of delivered gases when flows are decreased to $200 \mathrm{ml} / \mathrm{min}$. Many newer anesthesia machines have minimal flow requirements for oxygen $\left(\mathrm{O}_{2}\right)$ and ratio monitor/controls to ensure that a hypoxic mixture will not be delivered. These work well at flows of $1 \mathrm{~L} / \mathrm{min}$ or greater where $\mathrm{O}_{2}$ consumption is less than $25 \%$ of total flow, but as closed-circuit flows are approached, even the administration of air can result in hypoxic mixtures.

As one approaches closed-circuit flows, the incremental savings progressively diminish, resulting in large increases in effort for little additional advantage. For a 3-hour case and a $70 \mathrm{~kg}$ patient (cardiac output $=4.8$ $\mathrm{L} / \mathrm{min}$ ), the lower limit for cost may be as high as $\$ 13$ (or approximately $14 \mathrm{ml}$ of liquid isoflurane) to maintain 1.3 minimum alveolar concentration. This compares to initial costs of $\$ 19.20$ and postintervention costs of $\$ 15.16$. Therefore, despite these limitations, on average, decreasing flows at the Adult General Hospital resulted in a savings that is $50 \%$ of the way to a theoretic ideal.

Decreasing the cost of neuromuscular blocking drugs also has limitations. Waste of neuromuscular blocking drugs is a common problem. Even at a nonuniversity hospital, such as Hartford Hospital in Hartford, Connecticut, $25 \%$ of vecuronium may be discarded due to improper labeling or techniques (Dr. Linda Rice, personal communication). Selection of which neuromuscular blocking drug to use is limited by two factors: case duration and patient status. Pancuronium does not work well for short outpatient procedures. As the surgical population becomes older and with more concurrent medical illness, the appropriateness of the longer-acting drugs decreases. Even in a large university hospital setting, we were able to decrease neuromuscular blocking drug use by $38 \%$, most likely merely by eliminating the inappropriate use of short-acting drugs.

All savings must be weighed against the potential for increased anesthetic risk. Closed-circuit anesthesia has been demonstrated to be safe and effective.* For neuromuscular blocking drugs, these savings must be weighed against the costs of additional care needed as a result of inadvertent prolonged muscle paralysis or the need for reintubation secondary to unrecognized residual muscle paralysis. This cost is not solely monetary but may involve increased anxiety, stress, and discomfort for the patient. Because of the low frequency of reintubation as detected by the QA process, no difference resulting from cost containment measures could be detected.

Efforts to decrease the cost per case of volatile anesthetics and neuromuscular blocking drugs may shift the cost

*Ernst EA, MacKrell TN, Pearson JD, Cutter G, Wagenknecht L: Patient safety: a comparison of open and closed anesthesia circuits [Abstract]. Anesthesiology 1987;67:A474. 
to other drugs and regional anesthetic techniques. That is, propofol and regional block tray use may increase as a direct result of a drive to decrease the use of other drugs. Cost of commodities per case remained relatively level from 1989 through 1993, ranging from $\$ 116.45$ in 1991 to $\$ 104.83$ in 1993 . Given the effects of inflation, this finding can be construed as a reduction in the actual cost per case. To demonstrate a significant reduction in our anesthetic pharmacy costs (not utilization, as costs were held constant during this study), we need to assume an inflation rate of $8 \%$ per year over the 29 months of the study. This is further complicated by the fact that new drugs not studied here (for example, ondansetron) have been added to the formulary over this time period, increasing costs at the same time our cost reduction measures were in place.

Pharmaceutical companies have a huge and direct impact on cost that is outside the scope of the anesthesiologist's control. As a case in point, when the patent on isoflurane expires, any decrease in cost from competition among suppliers will decrease cost at any flow rate. From a medicolegal perspective, when a drug is restricted (such as the newest recommendations for succinylcholine) or withdrawn from use (such as hydralazine), usually more expensive alternatives must be used.

Educational measures require much reinforcement for both faculty and residents. Both are expected to be able to justify their choice of anesthetic technique and neuromuscular blocking drugs with regard not only to efficacy but also to cost-effectiveness. This justification takes place during the preoperative discussion between the resident and the faculty and between the faculty at a 7 A.M. meeting when the day's cases are discussed. Additionally, the authors and others on the team actively teach low-flow and closed-circuit anesthesia to demonstrate the principles of uptake and distribution of anesthetic drugs.

Other benefits of implementing these practices fall into two categories: one involves direct improvement in patient care due to the techniques used; the other involves improvement in patient care due to improved education. Low-flow anesthesia increases rebreathing not only of volatile anesthetic drug but also of the patient's own heat and humidity. Therefore, there is less need for external devices to heat or humidity respiratory gases. There is also less atmospheric pollution by these fluorocarbon compounds.

Education improves the use of volatile anesthetics. By understanding uptake and distribution, residents understand how to alter the flow of gases to change anesthetic depth rapidly. By clinicians being more rigorous in machine checkout, smaller leaks are detected. During anesthetic administration, the development of smaller leaks is more easily and quickly detectable. Education also improves the use of neuromuscular blocking drugs. There should be less "reflex" use of a drug and more titration to response, individualizing each dose to the patient and the clinical situation at hand.

Recommendations must be limited in scope, in part because determinants of cost vary by practitioner and institution. For anesthesiologists who are already choosing low-flow anesthesia and cost-effective use of neuromuscular blocking drugs, the changes in practice will be minimal. For those who are running $6 \mathrm{~L} / \mathrm{min}$ (or even $3 \mathrm{~L} / \mathrm{min}$ ) total flows and using vecuronium for every case, the benefits could be substantial. At institutions where the average case duration is under 1 hour, the impact will be less because the rate of uptake and cost of volatile anesthetics is greatest in the first minutes of anesthesia and the duration of the less expensive neuromuscular blocking drugs is too long.

\section{Acknowledgments}

We wish to acknowledge the help of Vikki Harrison and Steve Loney in obtaining the cost and case data, the assistance of Sally McDermott and Bill Fleishman in obtaining QA data, and the help of Jim Day in facilitating the quality improvement team meetings.

\section{References}

1. Johnstone RE, Martinec CL: Costs of anesthesia. Anesth Analg 1993;76:840-8.

2. Loke J. Shearer WA: Cost of anaesthesia [Letter]. Can J Anaesth 1993;40(5 Pt 1):472-4.

3. Deming WE: Out of the Crisis. Cambridge, MA: MIT Press, 1982: 86-94.

4. Wetchler BV: Economic impact of anesthesia decision making: they pay the money, we make the choice. J Clin Anesth 1992;4:(5 Suppl 1):20S-24S.

5. Sung YF, Reiss N, Tillette T: The differential cost of anesthesia and recovery with propofol-nitrous oxide anesthesia versus thiopental sodium-isoflurane-nitrous oxide anesthesia. J Clin Anesth $1991 ; 3: 391-4$.

6. Aldrete JA, Hendricks PL: Cost of muscle relaxant drugs [Letter]. Anesth Analg 1985;64:943-4.

7. Hamilton WK: Patient safety and cost containment. In: Gravenstein JS, Holzer JF (eds): Safety and Cost Containment in Anesthesia. Boston: Butterworths, 1988:3-10. 